Pesq. Vet. Bras. 36(4):279-282, abril 2016 DOI: $10.1590 / \mathrm{S} 0100-736 \mathrm{X} 2016000400005$

\title{
Atividade antibacteriana in vitro da própolis marrom ${ }^{1}$
}

\author{
Maria F.F. Gomes $^{2}$, Camila C.B.F. Ítavo ${ }^{2 *}$, Cássia R.B. Leal², Luís C.V. Ítavo² \\ e Resenângela C. Lunas ${ }^{2}$
}

\begin{abstract}
Gomes M.F.F., Ítavo C.C.B.F., Leal C.R.B., Ítavo L.C.V. \& Lunas R.C. 2016. [In vitro biological activity of brown propolis.] Atividade antibacteriana in vitro da própolis marrom. Pesquisa Veterinária Brasileira 36(4):279-282. Faculdade de Medicina Veterinária e Zootecnia, Universidade Federal de Mato Grosso do Sul, Av. Filinto Müller 2443, Ipiranga, Campo Grande, MS 79074-460, Brazil. E-mail: camila.itavo@ufms.br

The aim of this study was to evaluate the in vitro antibacterial activity of brown propolis, by determining the minimum inhibitory concentration (MIC). The alcoholic extract of propolis was obtained from $35 \mathrm{~g}$ of crude propolis macerated in $65 \mathrm{~mL}$ of cereals alcohol. Dilutions of propolis extracts used were: $75 \mathrm{mg} / \mathrm{mL} ; 56.4 \mathrm{mg} / \mathrm{mL} ; 37.5 \mathrm{mg} / \mathrm{mL} ; 18.9 \mathrm{mg} / \mathrm{mL}$; $9.3 \mathrm{mg} / \mathrm{mL} ; 4.5 \mathrm{mg} / \mathrm{mL}$, and $2.25 \mathrm{mg} / \mathrm{mL}$. Thirty-two Gram-positive bacteria isolates were used: Rhodococcus equi, Staphylococcus aureus, Staphylococcus hyicus, Staphylococcus spp. and Streptococcus spp.; and the thirty-two Gram-negative bacteria isolated were: Enterobacter agglomerans, Escherichia coli, Klebsiella pneumoniae, Klebsiella sp., Pseudomonas aeruginosa, Pseudomonas sp., Salmonella sp., and Serratia rubidaea, obtained from infectious clinical processes of domestic animals, and stored in the Laboratory of Bacteriology of FAMEZ/ UFMS. The brown propolis extract showed antibacterial activity with MIC ranging from 2.25 to $18.9 \mathrm{mg} / \mathrm{ml}$ for Gram-positive bacteria and 4.5 to $18.9 \mathrm{mg} / \mathrm{ml}$ for Gram-negative bacteria, and bacteria from cattle and dogs were more resistant. It was concluded that brown propolis has antibacterial action, but the effect depends on the species of the bacterium and its origin.
\end{abstract}

INDEX TERMS: Biological activity, brown propolis, bacteria, bactericidal, minimum inhibitory concentration.

\begin{abstract}
RESUMO.- Objetivou-se avaliar a atividade antibacteriana in vitro da própolis marrom, por meio da determinação da Concentração Inibitória Mínima (CIM). 0 extrato alcoólico de própolis foi obtido de $35 \mathrm{~g}$ de própolis bruta macerada em $65 \mathrm{~mL}$ de álcool de cereais. As concentrações do extrato de própolis usadas foram: $75 \mathrm{mg} / \mathrm{mL} ; 56,4 \mathrm{mg} / \mathrm{mL} ; 37,5 \mathrm{mg} / \mathrm{mL}$; $18,9 \mathrm{mg} / \mathrm{mL} ; 9,3 \mathrm{mg} / \mathrm{mL} ; 4,5 \mathrm{mg} / \mathrm{mL}$ e $2,25 \mathrm{mg} / \mathrm{mL}$. Foram utilizados 32 isolados de bactérias Gram-positivas: Rhodococcus equi, Staphylococcus aureus, Staphylococcus hyicus, Staphylococcus spp. e Streptococcus spp., e 32 isolados de bactérias Gram-negativas: Enterobacter agglomerans, Escherichia coli, Klebsiella pneumoniae, Klebsiella sp., Pseudomonas aeruginosa, Pseudomonas spp., Salmonella spp. e Serratia rubidaea, provenientes de processos clínicos infecciosos de animais

\footnotetext{
${ }^{1}$ Recebido em 25 de junho de 2015.

Aceito para publicação em 19 de janeiro de 2016.

${ }^{2}$ Faculdade de Medicina Veterinária e Zootecnia (FAMEZ), Universidade Federal de Mato Grosso do Sul (UFMS), Av. Filinto Müller 2443, Ipiranga, Campo Grande, MS 79074-460, Brasil. *Autor para correspondência: camila.itavo@ufms.br
}

domésticos, obtidas e armazenadas no Laboratório de Bacteriologia da FAMEZ/UFMS. 0 extrato de própolis marrom apresentou atividade antimicrobiana com CIM variando de 2,25 a 18,9mg/mL para as bactérias Gram-positivas e 4,5 a $18,9 \mathrm{mg} / \mathrm{mL}$ para as bactérias Gram-negativas, sendo as bactérias provenientes de bovinos e caninos as mais resistentes. Conclui-se que a própolis marrom tem ação bactericida, em função da espécie da bactéria e da procedência animal.

TERMOS DE INDEXAÇÃO: Atividade antibacteriana, própolis marrom, bactérias, bactericida, concentração inibitória mínima.

\section{INTRODUÇÃo}

A própolis é uma substância resinosa que as abelhas coletam de diversas partes das plantas, como brotos, botões florais, cascas e exsudatos resinosos (Park et al. 1998, Pereira et al. 2002). As abelhas utilizam a própolis para fechar pequenos orifícios, mumificar insetos que morrem no interior da colmeia, defender contra invasão de microrganismos, fortalecer os favos e proteger a entrada das colmeias (Marcucci 1996, Bankova et al. 2000). 
A própolis tem sido empregada como um importante fitoterápico devido aos estudos que revelaram seu potencial antibacteriano, anti-inflamatório, antiviral, antifúngico e imunomodulatório (Castro 2001, Sforcin \& Bankova 2011, Cabral et al. 2012, Portilho et al. 2013). Também, apresenta propriedades farmacoterapêuticas que a coloca como possível alternativa ao uso dos antibióticos. No entanto, há necessidade de uma padronização das doses e dos extratos (Coelho et al. 2010).

Em toda a extensão do território brasileiro são encontradas plantas apícolas produtoras de substrato para a composição e síntese de própolis. A grande diversidade dessas plantas, a época de coleta da resina, a genética das abelhas e a região geográfica proporcionam à própolis uma variada composição química (Marcucci 1996, Bankova et al. 2000, Orsi et al. 2005, Gonsales et al. 2006, Daugsch et al. 2008). As propriedades químicas da própolis apresentam importante valor farmacológico como um complexo natural e não como uma fonte de compostos que atuam isoladamente (Kujumgiev et al. 1999).

Diante do exposto, realizou-se este trabalho com o objetivo de avaliar a atividade antibacteriana da própolis marrom frente a bactérias isoladas de processos infecciosos de animais domésticos.

\section{MATERIAL E MÉTODOS}

A própolis bruta foi coletada das colmeias de abelha Apis mellifera, instaladas em apiário na Fazenda Escola da Faculdade de Medicina Veterinária e Zootecnia da Universidade Federal de Mato Grosso do Sul, situada no município de Terenos, MS $\left(20^{\circ} 26^{\prime} 34.31^{\prime \prime} S\right.$ $54^{\circ} 50^{\prime} 27.86^{\prime \prime} 0$, com $530,7 \mathrm{~m}$ de altitude). Para produção da própolis, entre os meses de maio a agosto, foram colocadas telas de nylon entre a melgueira e a tampa. Após 45 dias, as telas foram removidas, embaladas e transportadas até o laboratório de Apicultura da FAMEZ/UFMS, em Campo Grande, MS. A própolis foi proveniente da florada de plantas apícolas da região: Luehea sp. (açoita-cavalo), Piptadenia falcata (angico-do-cerrado), Tabebuia spp. (ipês), Tabebuia caraíba (para-tudo), predominando Vernonia spp. (assa-peixes) e Cecropia pachystachya (embaúba).

Para obtenção do extrato alcoólico de própolis, foram utilizadas $35 \mathrm{~g}$ da própolis bruta com agitação diária durante 45 dias em $65 \mathrm{~mL}$ de álcool de cereais. Posteriormente foi filtrada em papel de filtro, obtendo-se uma solução estoque, armazenada em frascos âmbar e mantida em temperatura ambiente. Analisaram-se os parâmetros físico-químicos (cera, resíduo seco, fenóis totais e flavonoides totais) adotados pela legislação brasileira vigente (Brasil 2001), segundo a metodologia descrita por Funari \& Ferro (2006).

0 protocolo experimental foi aprovado pelo Comitê de ética no

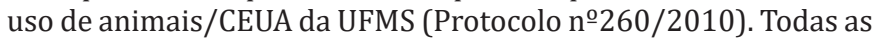
amostras de bactérias utilizadas neste estudo foram provenientes da bacterioteca do Laboratório de Bacteriologia da FAMEZ/ UFMS. As amostras foram obtidas de processos clínicos infecciosos de animais domésticos, sendo mantidas congeladas a $-20^{\circ} \mathrm{C}$, com criopreservante glicerol, na proporção v/v. Foram usadas 32 amostras de Gram-positivas e 32 amostras de Gram-negativas. A identificação das amostras, a espécie animal de origem e o número de isolados, estão demonstrados nas Quadros 1 e 2 , respectivamente, para as bactérias Gram-positivas e Gram-negativas.

A atividade antibacteriana do extrato alcoólico de própolis foi investigada por meio da determinação da Concentração Inibitória Mínima (CIM) pela técnica de sensibilidade por microdiluição em
Quadro 1. Concentração Inibitória Mínima (CIM) do extrato alcoólico de própolis marrom frente às bactérias Gram-positivas

\begin{tabular}{lccc}
\hline Bactérias & Procedência & № de isolados & CIM $(\mathrm{mg} / \mathrm{mL})$ \\
\hline Rhodococcus equi & Equina & 1 & 9,30 \\
Staphylococcus aureus & Bovina & 3 & $9,30(2 / 3)$ \\
& & & $18,90(1 / 3)$ \\
Ctaphylococcus hyicus & Camundongo & 1 & 4,50 \\
Ctaphylococcus spp. & Bovina & 1 & 4,50 \\
& Canina & 1 & 9,30 \\
& & & $2,25(9 / 21)$ \\
& & & $4,50(7 / 21)$ \\
& Felina & 1 & $9,30(4 / 21)$ \\
& Camundongo & 1 & 2,25 \\
Streptococcus spp. & Bovina & 1 & 9,30 \\
& Equina & 1 & 2,25 \\
& & & 2,25
\end{tabular}

Quadro 2. Concentração Inibitória Mínima (CIM) do extrato alcoólico de própolis marrom frente às bactérias Gram-negativas

\begin{tabular}{lccc}
\hline Bactérias & Procedência & № de isolados & CIM $(\mathrm{mg} / \mathrm{mL})$ \\
\hline Enterobacter agglomerans & Bovina & 2 & 9,30 \\
& Suína & 1 & 9,30 \\
Escherichia coli & Ave & 1 & 9,30 \\
& Bovina & 7 & $9,30(5 / 7)$ \\
& Canina & 3 & $18,90(2 / 7)$ \\
& Felina & 1 & 4,50 \\
Klebsiella pneumoniae & Canina & 2 & 4,50 \\
& Felina & 1 & $4,50-18,90$ \\
Klebsiella sp. & ATCC 13883 & 1 & 4,50 \\
Pseudomonas aeruginosa & Felina & 1 & 4,50 \\
& Felina & 3 & 9,30 \\
Pseudomonas spp. & & & $9,30(1 / 3)$ \\
& Bovina & 2 & 9,30 \\
Salmonella spp. & Canina & 3 & $4,50(1 / 3)$ \\
& & & $9,30(2 / 3)$ \\
Serratia rubidaea & Alimento & 1 & 9,30 \\
& Equina & 1 & 9,30 \\
& Bovina & 1 & 4,50 \\
& Felina & 1 & 9,30
\end{tabular}

a ATCC 13883 = American Type Culture Collection.

caldo, segundo protocolo descrito por Winn Jr et al. (2008), com modificações.

As amostras bacterianas foram reativadas em caldo infusão de cérebro e coração (BHI) e o teste de pureza e viabilidade realizado em Agar BHI. Foram escolhidas algumas colônias bem isoladas que foram repicadas em caldo BHI. A padronização do inóculo foi realizada pela equiparação da turvação do repique com o tubo 0,5 da escala de Mac Farland, que corresponde ao número de 1,5×10 bactérias $/ \mathrm{mL}$.

0 ensaio de sensibilidade foi executado em placas de microtitulação de 96 poços. As diluições do extrato de própolis usadas foram: $75 \mathrm{mg} / \mathrm{mL}, 56,4 \mathrm{mg} / \mathrm{mL}, 37,5 \mathrm{mg} / \mathrm{mL}, 18,9 \mathrm{mg} / \mathrm{mL}, 9,3 \mathrm{mg} /$ $\mathrm{mL}, 4,5 \mathrm{mg} / \mathrm{mL}$ e $2,25 \mathrm{mg} / \mathrm{mL}$. A cada poço foram adicionados $10 \mu \mathrm{L}$ do inóculo bacteriano. Controles foram usados empregando o inóculo bacteriano e álcool de cereais. Os ensaios foram realizados em duplicata/microrganismo/tratamento.

As placas contendo inóculo, e as diferentes concentrações do extrato, foram incubadas em estufa a $37^{\circ} \mathrm{C}$ por doze horas. Após esta etapa todos os poços foram semeados em placas de ágar BHI as quais foram incubadas a $37^{\circ} \mathrm{C}$ por uma noite. A leitura das placas foi realizada pela observação do crescimento das colônias. 


\section{RESULTADOS E DISCUSSÃO}

O extrato alcoólico de própolis $35 \%$ apresentou $29,90 \mathrm{mg} /$ $\mathrm{mL}$ de cera, $151,28 \mathrm{mg} / \mathrm{mL}$ de resíduo seco, $13,95 \mathrm{mg} / \mathrm{mL}$ de flavonoides totais e $27,65 \mathrm{mg} / \mathrm{mL}$ de fenóis totais. 0 teor de compostos fenólicos do extrato de própolis marrom deste ensaio é semelhante aos $2,61 \%(26,1 \mathrm{mg} / \mathrm{mL})$, encontrado no extrato de própolis proveniente de Prudentópolis, PR analisado por Buriol et al. (2009), entretanto o teor de flavonóides é superior aos $0,46 \%(4,6 \mathrm{mg} / \mathrm{mL})$. Há de se destacar que ambos os extratos estão dentro dos limites estabelecidos pela legislação brasileira, na qual o teor de flavonoides da própolis é de $0,25 \%$ - mínimo $(2,5 \mathrm{mg} / \mathrm{mL})$ e para os compostos fenólicos 0,50\% - mínimo $(5,0 \mathrm{mg} / \mathrm{mL})$ (Brasil 2001).

Foi verificado que o extrato alcoólico de própolis apresentou atividade antimicrobiana para todas as bactérias Gram-positivas (Quadro 1) e Gram-negativas (Quadro 2) utilizadas nesta pesquisa, no entanto, com diferentes CIM, dependendo da espécie e do isolado, conferindo a própolis uma possível aplicação como substância antibacteriana.

Para as bactérias Gram-positivas, a CIM do extrato alcoólico de própolis variou de 2,25 a 18,5mg/mL. A menor CIM do extrato alcoólico de própolis capaz de inibir o crescimento de Streptococcus spp. de procedência bovina foi $2,25 \mathrm{mg} / \mathrm{mL}$. Para as bactérias do gênero Staphylococcus, também de procedência bovina a CIM foi $9,3 \mathrm{mg} / \mathrm{mL}$, indicando maior resistência desse gênero ao extrato de própolis quando comparada ao gênero Streptococcus, o que é esperado, uma vez que bactérias do gênero Staphylococcus possuem maior habilidade em desenvolver resistência a compostos em geral, sendo utilizada como um microrganismo de referência em testes de resistência.

Resultados positivos também foram encontrados por Saeki et al. (2011), em que o extrato alcoólico de própolis a 30\% foi eficaz contra Staphylococcus aureus proveniente de animais portadores de mastite, apresentando um halo de inibição entre 6 e $18 \mathrm{~mm}$, sugerindo como alternativa ao uso dos antibióticos comerciais. Apesar da técnica de difusão de discos ser amplamente utilizada para ensaios antibacterianos, tal técnica possui como limitação o fato de não indicar a quantidade exata do composto necessária pra inibir uma determinada concentração bacteriana.

Serra Bonvehí et al. (1994) encontraram ação bactericida da própolis bruta, de origem brasileira, para Staphylococcus aureus com uma CIM de $0,1 \mathrm{mg} / \mathrm{mL}$, valor inferior aos $9,3 \mathrm{mg} / \mathrm{mL}$ encontrados neste ensaio, o que demonstra maior atividade inibitória da própolis testada por estes autores. Vale ressaltar que no presente ensaio, a procedência clínica dos microrganismos testados pode ter influenciado na eficácia da inibição do crescimento bacteriano.

Neste trabalho verificou-se que, o extrato alcoólico de própolis 35\% apresentou ação antibacteriana com concentração inibitória mínima variando de 4,5 a $18,9 \mathrm{mg} / \mathrm{mL}$ para Escherichia coli e de 4,5 a 9,3mg/mL para Pseudomonas aeruginosa. Valores com concentrações inibitórias superiores foram encontrados por Sforcin et al. (2000), usando extrato de própolis $30 \%$, sendo a CIM de $5,70 \%(57 \mathrm{mg} / \mathrm{mL})$ para Pseudomonas aeruginosa e de 6,33 a 8,00\% (63,3-80,0mg/ $\mathrm{mL)}$ para Escherichia coli, o que pode estar relacionado ao fato das amostras de bactérias serem provenientes de pacientes humanos, provavelmente, em tratamento, o que torna estes isolados com possibilidade de apresentação de maior resistência a antimicrobianos.

Estes valores foram superiores aos encontrados para as bactérias Gram-positivas, o que é esperado, considerando-se que a parede celular das bactérias Gram-negativas é mais fina que a das bactérias Gram-positivas, porém mais complexa, devido ao lipopolissacarídeo (LPS), sendo a ação sobre este tipo de estrutura um desafio para os testes com antibacterianos (Winn Jr et al. 2008).

As investigações realizadas por Mirzoeva et al. (1997) corroboraram com os resultados obtidos nesse estudo. Neste estudo, o extrato de própolis apresentou atividade antimicrobiana sobre bactérias Gram-negativas, com concentração inibitória mínima (CIM) entre 4,5 e 18,9mg/ $\mathrm{mL}$, e sobre bactérias Gram-positivas com CIM entre 2,25 e $18,9 \mathrm{mg} / \mathrm{mL}$.

Siripatrawan et al. (2013), utilizando própolis tailandesa extraída com etanol $30,40,50 \%$, verificaram que os extratos de própolis demonstraram atividade antibacteriana frente a Staphylococcus aureus TISTR 118, no entanto, não exibindo halo de inibição com extrato $70 \%$ e, nenhuma dessas concentrações apresentou efeito inibitório frente a Escherichia coli TISTR 780, Pseudomonas aeruginosa ATCC 27853 e Salmonella enteritidis DMTS 17368. Já Orsi et al. (2005), utilizando extratos de própolis provenientes de duas regiões do Brasil, verificaram efeito bactericida do extrato de própolis frente à Salmonella spp, assim como neste ensaio, no qual obteve-se CIM entre 4,5 e 9,3mg/mL (Quadro 2).

De acordo com Stepanović et al. (2003), independentemente da resistência microbiana aos antibióticos, o extrato de própolis (2g própolis bruta e $10 \mathrm{~mL}$ etanol 95\%) mostrou significativa atividade antimicrobiana contra bactérias Gram-positivas (CIM 0,78mg/mL a $12,5 \mathrm{mg} / \mathrm{mL}$ de extrato etanólico de própolis), enquanto as bactérias Gram-negativas foram menos suscetíveis $112,5 \mathrm{mg} / \mathrm{mL}$ a $>50 \mathrm{mg} / \mathrm{mL}$ de extrato etanólico de própolis). Os valores encontrados por estes autores para Staphylococcus aureus foram entre $0,78 \mathrm{mg} / \mathrm{mL}$ e $3,1 \mathrm{mg} / \mathrm{mL}$, inferiores aos obtidos no presente trabalho (Quadro 1). Já para Escherichia coli e Pseudomonas aeruginosa, Stepanović et al. (2003) encontraram $12,5 \mathrm{mg} / \mathrm{mL}$ e $>50 \mathrm{mg} / \mathrm{mL}$, respectivamente, ambos valores superiores aos encontrados no presente estudo (Quadro 2).

Bactérias de procedência bovinas e caninas apresentaram maior resistência, provavelmente pelo histórico de tratamento destes animais, marcado pelo uso indiscriminado de antimicrobiano, acarretando seleção de populações bacterianas mais resistentes.

O emprego da própolis como antibiótico natural seria possivelmente mais viável para o tratamento de infecções provocadas por bactérias Gram-positivas, com formulações que permitissem o uso tópico, a exemplo do que é praticado em infecções da via respiratória superior e na odontologia. Pesquisas com o extrato etanólico de própolis comprovaram a inibição do microrganismo Streptococcus mutans causador da cárie dentária (Park et al. 1998, Alves et al. 2006). Outro uso possível foi efetuado como extrato 
hidrossolúvel de própolis na pré e pós-imersão dos tetos de bovinos leiteiros na prevenção da mastite bovina (Andrade 2010).

\section{CONCLUSÃO}

A própolis marrom, utilizada como extrato alcoólico 35\%, tem ação bactericida frente às bactérias Gram-positivas e Gram-negativas utilizadas neste estudo, apresentando diferentes concentrações inibitórias mínimas, dependendo da espécie, do microrganismo e de sua procedência, sendo as de origem bovina e canina as mais resistentes.

\section{REFERÊNCIAS}

Alves F.B.C., Barreto L.M.R.C., Jorge A.C.C. \& Santos S.S.F. 2006. Eficiência de soluções aquosas e hidroalcoólicas da própolis do Vale da Paraíba sobre cepas Streptococcus mutans. Revta Biociência 12:74-81.

Andrade U.V.C. 2010. Potencial antibacteriano do extrato hidrossolúvel de própolis obtido por hidrólise alcalina para a inibição de cultivos de Staphylococcus aureus e higienização de pré e pós-imersão de tetos de vacas leiteiras. Tese de Doutorado, Universidade Federal do Paraná, Curitiba. 85p.

Bankova V.S., Castro S.L. \& Marcucci M.C. 2000. Propolis: recent advances in chemistry and plant origin. Apidologie 31:3-15.

Brasil 2011. Legislação. Instrução Normativa n.3, de 19 de Janeiro de 2001, aprova os Regulamentos Técnicos de Identidade e Qualidade de Apitoxina, Cera de Abelha, Geleia Real, Pólen Apícola, Própolis e Extrato de Própolis. Agência Nacional de Vigilância Sanitária, Ministério da Saúde, Brasília.

Buriol L., Finger D., Schmidt E.M., Santos J.M.T., Rosa M.R., Quináia S.P. \& Torres Y.R. 2009. Composição química e atividade biológica de extrato oleoso de própolis: uma alternativa ao extrato etanólico. Química Nova 32:296-302.

Cabral I.S.R., Oldoni T.L.C., Alencar S.M., Rosalen P.L. \& Ikegaki M. 2012. The correlation between the phenolic composition and biological activities of two varieties of Brazilian propolis (G6 and G12). Braz. J. Pharm. Sci. 48:557-564.

Castro S.L. 2001. Propolis: biological and pharmacological activities: therapeutic uses of this bee-product. Annu. Rev. Biomed. Sci. 3:49-83.

Coelho M.S., Silva J.H.V., Oliveira E.R.A., Amâncio A.L.L., Silva N.V. \& Lima R.M.B. 2010. A própolis e sua utilização em animais de produção. Archs Zootecnia 59:95-112.

Daugsch A., Moraes C.S., Fort P. \& Park Y.K. 2008. Brazilian red propolis - chemical composition and botanical origin. Evidence-Based Complementary and Alternative Medicine 5:435-441.
Funari C.S. \& Ferro V.O. 2006. Análise de própolis. Ciênc. Tecnol. Alimentos 26:171-178.

Gonsales G.Z., Orsi R.O., Fernandes Júnior A., Rodrigues P. \& Funari S.R.C. 2006. Antibacterial activity of propolis collected in different regions of Brazil. J. Venom. Anim. Toxins incl. Trop. Dis. 12:276-284.

Kujumgiev A., Tsvetkova I., Serkedjieva Y., Bankova V., Christov R. \& Popov S. 1999. Antibacterial, antifungical, and antiviral activity of propolis of different geographic origin. J. Ethnopharmacol. 64:235-240.

Marcucci M.C. 1996. Propriedades biológicas e terapêuticas dos constituintes químicos da própolis. Química Nova 19:529-536.

Mirzoeva O.K., Grishanin R.N. \& Calder P.C. 1997. Antimicrobial action of propolis and some of its components: the effects on growth, membrane potential and motility of bacteria. Microbiol. Res. 152:239-246.

Orsi R.O., Sforcin J.M., Rall V.L.M., Funari S.R.C., Barbosa L. \& Fernandes Júnior A. 2005. Susceptibility profile of Salmonella against the antibacterial activity of propolis produced in two regions of Brazil. J. Venom. Anim. Toxins incl. Trop. Dis. 11:109-116.

Park Y.K., Koo M.H., Abreu J.A.S., Ikegaki M., Cury J.A. \& Rosalen P.L. 1998. Antimicrobial activity of propolis on oral microorganisms. Current Microbiology 36:24-28.

Pereira A.S., Seixas F.R.M.S. \& Aquino Neto F. R. 2002. Própolis: 100 anos de pesquisa e suas perspectivas futuras. Química Nova 25:321-326.

Portilho D.R., Melo I.A., Guerra R.C., Batista H.L. \& Fernandes C.H.C. 2013. Avaliação da atividade antibacteriana e antifúngica da própolis produzida no Estado de Tocantins. Revta Cient. ITPAC 6:1-8.

Saeki E.K., Peixoto E.C.T.M., Matsumoto L.S., Marcusso P.F. \& Monteiro R.M. 2011. Mastite bovina por Staphylococcus aureus: sensibilidade às drogas antimicrobianas e ao extrato alcoólico de própolis. Acta Vet. Brasilica 5:284-290.

Serra Bonvehí J., Coll F.V. \& Jordà R.S. 1994. The composition, active components and bacteriostatic activity of propolis in dietetics. J. Am. Oil Chem. Soc. 71:529-532.

Sforcin J.M., Fernandes Júnior A., Lopes C.A.M., Bankova V. \& Funari S.R.C. 2000. Seasonal effect on Brazilian propolis antibacterial activity. J. Ethnopharmacology 73:243-249.

Sforcin J.M. \& Bankova V. 2011. Propolis: is there a potential for the development of new drugs? J. Ethnopharmacology 133:253-260.

Siripatrawan U., Vitchayakitti W. \& Sanguandeekul R. 2013. Antioxidant and antimicrobial properties of Thai propolis extracted using ethanol aqueous solution. Int. J. Food Sci. Technol. 48:22-27.

Stepanović S., Antić N., Dakić I. \& Švabić-Vlahovića M. 2003. In vitro antimicrobial activity of propolis and synergism between propolis and antimicrobial drugs. Microbiol. Res. 158:353-357.

Winn Júnior W., Allen S., Janda W., Koneman E., Procop G., Schreckenberger P. \& Woods G. 2008. Diagnóstico Microbiológico: texto e atlas colorido. Guanabara Koogan, Rio de Janeiro. 1465p. 